\title{
Hematologic Improvement-Platelet Response
}

National Cancer Institute

\section{Source}

National Cancer Institute. Hematologic Improvement-Platelet Response. NCI Thesaurus.

Code C123587.

An improvement of platelet count as a response to treatment. 